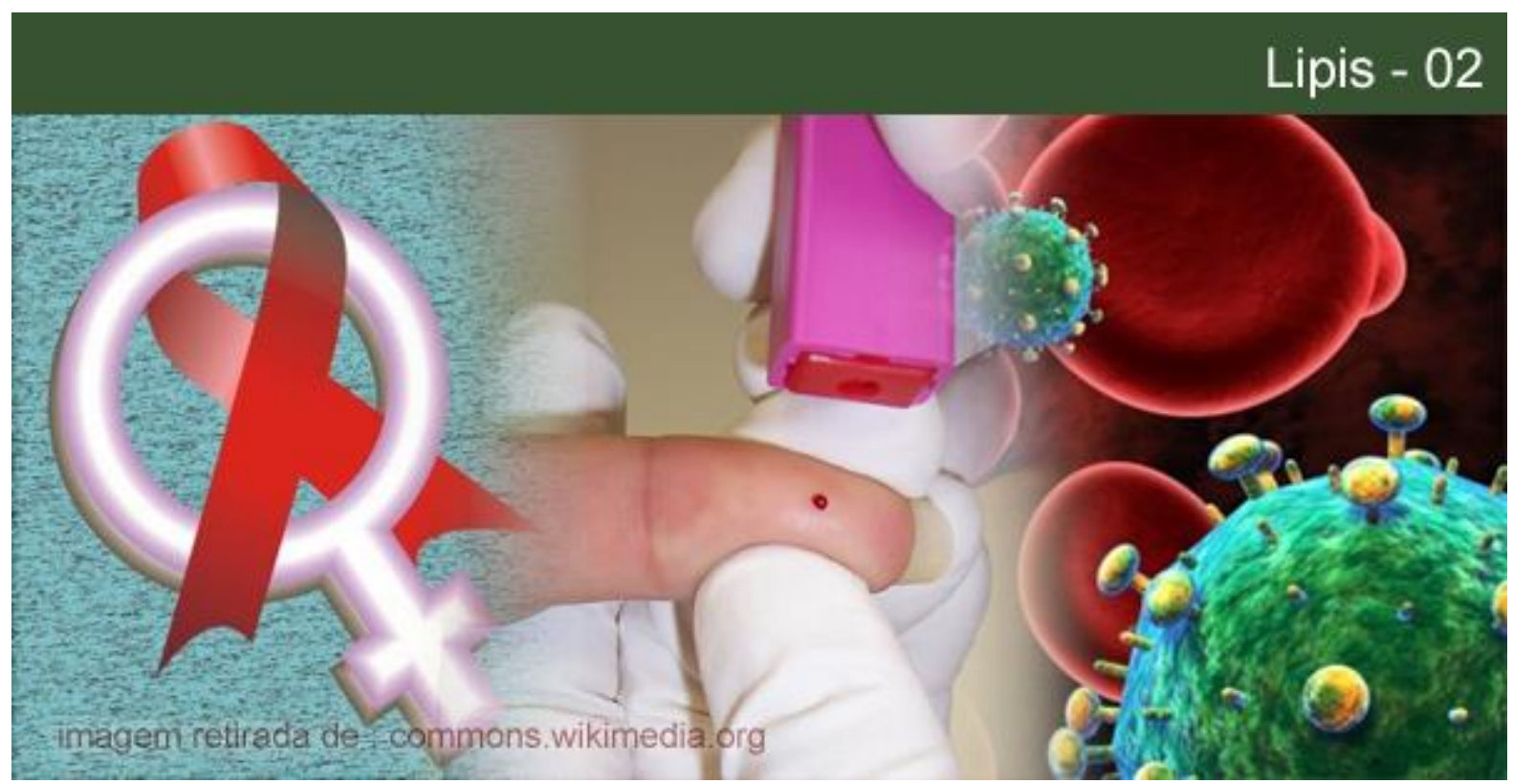

\title{
A FEMINIZAÇÃO DA AIDS: EFEITOS DA MORAL MÉDICA
}

\section{Bárbara Araújo Sordi}

Psicóloga Clinica e Hospitalar. Especialista em Psicologia da Saúde e Hospitalar. Mestranda em Psicologia Social, na linha Psicanálise: teoria e clinica. Pesquisadora sobre relações de gênero, feminização da aids e psicanálise. Participante do Laboratório de Psicopatologia Fundamental. Psicanalista em formação pelo Circulo Psicanalítico de Minas Gerais. E-mail: barbarasordi@hotmail.com.

\section{Carolina de Sousa Malcher}

Psicóloga e bacharel em Comunicação Social. Especialista em Psicologia da Saúde e Hospitalar e em Teoria Psicanalítica. Mestranda do Programa de Pós-Graduação em Psicologia da Universidade Federal do Pará (UFPa), na linha de pesquisa Psicologia, Sociedade e Saúde.

\section{Maria Lúcia Chaves Lima}

Doutora em Psicologia Social pela Pontifícia Universidade de São Paulo. Professora do Programa de PósGraduação em Psicologia e do Instituto de Ciências da Educação da Universidade Federal do Pará. Pesquisadora com experiência nas áreas de Psicologia Social e Educação, atuando principalmente nos seguintes temas: diversidade sexual, relações de gênero, masculinidades, violência contra a mulher, governamentalidade e modos de subjetivação. Coordena o grupo inquietAÇÕES: arte, saúde e educação. $E$ integrante do Núcleo de Práticas Discursivas e Produção de Sentidos da PUC-SP e membro da Associação Brasileira de Psicologia Social (ABRAPSO).

\section{Ana Cleide Guedes Moreira}

Psicóloga pela Universidade Federal do Pará (1982), mestrado (1992) e doutorado (2000) em Psicologia Clínica pela Pontifícia Universidade Católica de São Paulo, Pós-Doutorado em Psicologia Clínica na Universidade Paris 7. Atualmente é Professora Associada da Universidade Federal do Pará, leciona na Graduação e Pós-Graduação em Psicologia, Mestrado e Doutorado, onde coordena o Programa e dirige o Laboratório de Psicanálise e Psicopatologia Fundamental, grupo de pesquisa presente do Diretório de Grupos do CNPQ desde 2002. Tem experiência na área de Psicologia e Psicanálise, com ênfase em Intervenção Terapêutica e Análise em Instituições Hospitalares e Sistema Único de Saúde, pesquisando, principalmente os seguintes temas: melancolia e estados depressivos, psicopatologia fundamental, pensamento freudiano, dispositivos clínicos, relações de gênero e aids. Membro fundador e pesquisador da Associação Universitária de

\section{POLÊM!CA | Revista Eletronica da Uej}


Pesquisa em Psicopatologia Fundamental. Pesquisadora do Grupo de Estudos e Pesquisas Eneida de Moraes sobre Mulher e Relações de Gênero GEPEM-UFPA. Membro do GT da ANPEPP Psicopatologia e Psicanálise. Pesquisadora visitante do Laboratório Interdisciplinar de Pesquisa e Intervenção Social PUC-Rio. Chercheur associé à l Université Paris 7 Denis-Diderot. Membro da Réseau Internacional de Psychopathologie Transculturelle.

Resumo: Apesar dos avanços medicamentosos, a aids ainda é um grave problema de saúde pública que afronta a ciência pela alta incidência de transmissão e de número de óbitos. Considerada inicialmente como doença exclusiva de determinados grupos de risco, a aids alastrou-se silenciosamente entre as mulheres, que de maneira ilusória acreditavam estar imunes e protegidas do HIV. Desde 1990, a feminização da epidemia tornou-se uma realidade evidente pela alta incidência de novos casos. Entretanto, verifica-se que houve morosidade no reconhecimento da mulher enquanto vulnerável à infecção do vírus pela ciência médica, fato que ainda pode ser verificado nos dias atuais pelas ineficazes campanhas preventivas e pouca visibilidade de debates sobre feminização. Partindo da arqueologia de Foucault como orientação metodológica, este trabalho se propõe realizar uma breve digressão histórica sobre o saber médico e de como o discurso da medicina se utilizou de concepções morais em sua construção histórica, com o fim de refletir sobre a influência da cultura heteronormativa nas práticas médicas e suas implicações na feminização da epidemia, que trouxe consequências catastróficas para as mulheres, contribuindo para sua exposição à contaminação.

Palavras-chaves: Aids. Feminização. Moral médica.

\title{
AIDS FEMINIZATION: EFFECTS OF MEDICAL MORALITY
}

\begin{abstract}
In despite of medical advances, aids is still a serious public health problem that affronts science by the high incidence of transmission and number of deaths. First considered as an exclusive disease of certain risk groups, aids has silently spread among women that, in a illusory way, believed to be immune and protected from HIV. Since 1990, the epidemic feminization became an obvious reality because of the high incidence of new cases. However, it appears that the recognition of women as vulnerable to virus infection by medical science was delayed, which can still be seen today by ineffective prevention campaigns and low visibility of debates about feminization. Starting from Foucault's archeology as methodological guidance, this work intends to make a brief historical digression on medical knowledge and how the discourse of medicine had used moral concepts in their historical construction in order to reflect about the influence of heteronormative culture in medical practices and their implications for the epidemic feminization, which brought catastrophic consequences for women, contributing to its exposure to contamination.
\end{abstract}

Keywords: Aids; Feminization; Medical morality.

\section{Aids: problema de mulher}

No final da década de 1970, a medicina passou a se deparar com um novo padrão de doenças que se espalhava e afetava um número crescente de pessoas, causando uma ruptura à estabilidade alcançada pela descoberta dos antibióticos e vacinas. A nova patologia do HIV parecia interditar a ciência médica, que se via como emissária de um grave problema contra o qual não possuía solução e sequer conhecia sua etiologia. Assim, impotente diante da gravidade dos quadros clínicos e, conseguinte, da morte, a medicina contentava-se em caracterizar o doente apenas por sintomas clínicos evidentes, que pareciam atestar a finitude humana (LABAKI, 2001).

Diante desse sombrio cenário e da emergência em corresponder as expectativas sociais de forma a evitar novas contaminações, a comunidade científica iniciou suas primeiras

\section{POLÊM!CA | Revista Eletronica da Ueji}


campanhas preventivas identificando grupos de risco com os quais se deveria evitar o contato sexual: gays, prostitutas, usuários de drogas, hemofílicos e haitianos.

Eis o surgimento da associação da aids à transgressão e promiscuidade que se disseminou no imaginário popular, incitando preconceitos e iniqüidade que perduram até a atualidade. A associação da aids a uma "epidemia da imoralidade" ou uma "peste gay" fez com que o vírus se alastrasse silenciosamente entre mulheres, que, de forma ilusória, acreditavam estar imunes e protegidas da contaminação.

Mesmo com a descoberta da etiologia do vírus em 1984, apenas por volta da década de 1990 a contaminação de mulheres foi reconhecida como uma realidade evidente no mundo e no Brasil pela alta incidência de novos casos e de óbitos, passando a ser notificada pelo Ministério da Saúde, fenômeno chamado de feminização.

Sendo a aids uma doença sexualmente transmissível, o que fez com que por dez anos a medicina não considerasse o risco de contaminação em mulheres? Partindo como orientação metodológica a arqueologia do filósofo francês Michel Foucault, este trabalho se propõe realizar uma breve digressão histórica sobre o saber médico e de como o discurso da medicina se utilizou de concepções morais em sua construção histórica. Trata-se, portanto, de uma reflexão sobre a influência da cultura heteronormativa nas práticas médicas e suas implicações na feminização da epidemia da aids, aspecto que contribui até hoje para a exposição de mulheres à contaminação.

\section{O inicio da aids: a "invisível" vulnerabilidade feminina}

Entre avanços científicos e tecnológicos, estudos revelam que a ciência médica negligenciou dados relevantes que contribuíram para disseminação silenciosa do vírus entre mulheres, como apresentado a seguir.

Na década de 1980, já após a descoberta da etiologia do HIV, realizou-se um estudo através de amostras de tecido e sangue armazenados, em que foram descobertos 6 casos específicos relacionados a síndrome e que ocorreram antes da década de 1970. Entre eles, um marinheiro, sua esposa e sua filha na Noruega, que iniciaram o adoecimento nos anos 1960 e faleceram em 1973. Apesar de uma mulher e uma criança do sexo feminino estarem contaminadas, o caso não teve divulgação necessária, nem tomou relevância entre os estudos científicos (BERER \& RAY, 2007).

\section{POLÊM!CA | Revista Eletronica da veri}


No período entre 1981 e 1986, na área metropolitana de Nova York, o número de mortes de mulheres entre 15 e 44 anos por causas incomuns - como pneumonia, tuberculose, septicemia e infecções parasitárias raras - aumentou enormemente. No entanto, essas mortes ainda não eram tidas como consequência da aids. Apenas testes realizados em um momento posterior confirmaram que estavam relacionadas (BERER \& RAY, 2007).

O sub-registro desses casos também foi determinado por dois fatores centrais que permeiam a epidemia até os dias atuais: vergonha e medo da discriminação. De acordo com o relato de parentes das vítimas, diante da possibilidade de confirmar a presença do vírus, muitos optaram por desconhecer a causa do óbito, evitando maior sofrimento à família e, principalmente, preservando a imagem do membro familiar falecido (BERER \& RAY, 2007).

Porém, não foi apenas vergonha e medo da discriminação que culminaram para a não notificação da aids em mulheres. Por volta de 1986, os pesquisadores dos Centros de Controle e Doenças (CDCs), localizados nos Estados Unidos da América, ao se depararem com casos que ainda consideravam obscuros, dentre os quais constataram um elevado contingente de mulheres, passaram a reclassificar tais casos como "outros", não dando a atenção devida para o desenvolvimento de pesquisas que culminassem em tratamento e medidas preventivas (BARBOSA, 1995).

Pode-se pensar que não isolar e classificar a categoria "mulheres" trouxe, por um período, a obscuridade de informações, o que afetou dados estatísticos e os subsídios que eles fornecem, além de, consequentemente, causar a invisibilidade da vulnerabilidade às quais as mulheres estavam expostas, prejudicando estudos pertinentes que avaliassem as variáveis de exposição ao risco, políticas de prevenção e a autonomia da mulher no cuidado consigo.

Somente ao final da década de 1980 houve um incentivo à pesquisas, ações de educação pública, de prevenção e projetos de tratamento enfocando a mulher. Tais ações foram mobilizadas pelo fato de que durante a segunda metade da década de 1980, a aids se transformou na principal causa de mortalidade de mulheres em idade reprodutiva em muitas partes do mundo, como na África (BERER \& RAY, 2007).

Mesmo assim, ainda há escassez de estudos e de reconhecimento da possibilidade de contaminação feminina, aspecto que pode ser confirmado observando a condução da ciência no início da epidemia: a aids só obteve reconhecimento oficial como uma questão de mulher em novembro de 1989 . Apenas a partir da $8^{\circ}$ conferência internacional sobre aids, realizada

\section{POLÊM!CA | Revista Eletronica da Ueij}


em julho de 1992, em Amsterdã, passou-se a ter maior atenção profissional sobre a temática (BERER \& RAY, 2007).

Além do reconhecimento tardio da contaminação em mulheres, durante a década de 1980 e metade da década de 1990 houve um conflito em torno da inclusão da mulher nos ensaios clínicos com novas drogas de combate ao HIV, pois, em obediência à regulamentação emitida em 1977 pela FDA (Food and Drug Administration) ${ }^{1}$, mulheres em idade fértil (as mais afetadas pela epidemia) eram excluídas dos estudos até que fosse demonstrada a não teratogenicidade desses produtos, ou seja, a impossibilidade de ocasionar lesão em fetos (BASTOS, 2001).

Essa não inclusão acabou por determinar um impacto substancial sobre a não disponibilidade de novos produtos para as mulheres, prejudicando o efetivo acesso de mulheres gravemente enfermas a produtos essenciais à sua sobrevivência (B ASTOS, 2001).

Apenas em 1993 houve a adoção de novas regras "inclusivas" em relação às mulheres e, em parte, aos pacientes pediátricos. Atualmente, o maior sucesso na luta contra a aids, em termos de medicina e saúde pública, provém exatamente da inclusão de mulheres em protocolos clínicos antirretrovirais, diminuindo significativamente a transmissão em mulheres grávidas para os seus bebês, desde que submetidas ao tratamento adequado (BASTOS, 2001).

Outro fator que merece destaque é em relação aos preservativos femininos. O primeiro preservativo feminino foi lançado em 1920, na Inglaterra. Todavia, o investimento em pesquisa e divulgação foi abandonado até 1987, quando uma equipe dinamarquesa de médicos coordenada por Lasse Hessel produziu uma nova versão, que também não se expandiu. Em 1992, após uma década da epidemia, a companhia inglesa Chartex Internacional comprou seus direitos, investiu em pesquisas e lançou uma marca, com o nome "Femidom" no Reino Unido, "Reality" nos Estados Unidos e "Femi" em outros países, que passou ser comercializada, mesmo que timidamente, isto é, com pouca divulgação e esclarecimento (JAMES \& WERJ, 1997; KALCKMANN, 2013).

Nota-se que, precocemente, cientistas tiveram contato com a existência de mulheres contaminadas, tal como o caso relatado da família norueguesa, que já acusava a aids em um seio familiar. Entretanto, verifica-se que o discurso moral na medicina teve direta implicação

\footnotetext{
${ }^{1}$ Órgão regulador norte-americano, pela dimensão da indústria farmacêutica e do mercado consumidos dos Estados Unidos da América (EUA).
} 
em suas práticas e em seu saber, reconhecendo e tratando a aids como risco para as mulheres apenas uma década depois da explosão do vírus.

Ao associar a aids a práticas sexuais tidas como "imorais", a medicina iniciou sua concepção de "grupo de riscos" e apenas as profíssionais do sexo foram tidas como possíveis vulneráveis. Entretanto, desde a descoberta da etiologia do vírus, a ciência médica já obtinha as informações necessárias para compreender que toda e qualquer prática sexual sem preservativo - independente de cor, raça, classe social e estado civil - poderia expor à contaminação, fato que não ocorreu pela moralidade discursiva presente na ciência médica.

\section{A formação da moral médica e seus efeitos biopolíticos}

Para compreender o discurso médico, sua normatização, e relação com as concepções morais, recorreremos à concepção da arqueologia produzida por Michel Foucault (1926a/2008), que interroga as condições de existência dos discursos, incluindo os científicos. Portanto, para falar do processo de moralização da medicina é importante citar a famosa obra intitulada A História da Loucura, texto considerado uma crítica à razão, aos seus fundamentos e àquilo que a legitima. Aponta especificamente para as mudanças na compreensão teórica da loucura e das práticas da Idade Clássica para a Moderna.

$\mathrm{Na}$ Idade Média, o louco ainda estava integrado, sendo considerado diferente por ter acesso a um saber específico. A percepção da loucura na Idade Clássica estava associada à moral, um mau costume. O que marcou essa passagem foi a instauração da razão e de uma racionalidade que passou a ser o princípio norteador. Pensar passa a significar uma capacidade de classificar em gêneros e espécies, amparada na idéia de representação. $O$ pensamento representa as coisas (FOUCAULT, 1926a/2008).

A partir da ausência da razão, o louco passou então a ser incluído na categoria da desrazão. Aquele que atenta contra as regras da moralidade, da convivência social, misturado às prostitutas, aos homossexuais, sodomitas, vistos como uma ameaça ao social. O louco é excluído da lógica do pensamento, não sendo um ser racional e impossibilitado de chegar à verdade por meio do método. O louco não era visto como diferente daqueles que estavam no hospital. Nessa época, a transgressão era punida e uma das formas era hospitalizar, por exemplo, o doente venéreo, por ser aquele que adquiriu a doença fora de casa (FOUCAULT, 1926a/2008).

\section{POLÊM!CA | Revista Eletronica da Uerj}


O louco, por ser incapaz de pensar; a prostituta, por atentar contra a família higiênica, propagando doenças; da mesma forma os homossexuais e sodomitas que desvirtuavam a verdadeira função sexual destinada somente à reprodução e boa manutenção da ordem. O que vemos é o estabelecimento de uma relação entre comportamento fora do padrão estabelecido como uma causa de adoecimento. Ao afirmar isto, podemos pensar na expressão comportamento ou grupo de risco, ainda hoje propagada em algumas práticas discursivas que se referem à epidemia do HIV.

Buscando relacionar o saber científico da medicina à moral, entendemos que esta remete ao conjunto das proibições e, entendida como aquilo que é permitido e o não permitido pela sociedade, revelando uma repressão de dupla eficácia: a cura dos corpos e purificação das almas, "para o bem", no âmbito da escola, da família, da educação e assim por diante. Temos assim, a desrazão configurada na prática, através das instituições como o hospital, considerado na época, um lugar de passagem, de repressão, sem função de cura e sim moralização das pessoas que eram conduzidas até lá (FOUCAULT, 1926a/2008).

$\mathrm{Na}$ história de nossa civilização, fomos atravessados na construção dessa moral médica, e, também, pelo cristianismo, em uma espécie de coação e repressão, revelando um poder que produz seres sujeitados a uma norma. $\mathrm{O}$ poder da norma associada à medicina, como algo que é natural. O normal é aquilo que faz parte naturalmente. Um movimento da ciência em que naturaliza a idéia de essência e de uma norma que legisla sobre a anormalidade (FOUCAULT, 1926a/2008).

Na psiquiatria, a percepção social (ordem moral, desordem de hábitos e costumes), e a percepção teórica (associada à questão da doença) da loucura assumem a concepção médica na idéia do saudável e do doente. O nascimento da psiquiatria é entendido como o nascimento de um discurso da moralidade, representando uma capa científica ao discurso da moralidade (FOUCAULT, 1926a/2008).

Desse modo, tudo aquilo que não enquadre ou que foge à regra estabelecida pela medicina, é considerado como um desvio, uma patologia. Normatizar os chamados "comportamentos de risco" assim como conceber um discurso sobre o matrimônio como uma forma segura de manter a saúde, passaram a permear o imaginário social com a credibilidade científica do discurso médico. Em a História da Sexualidade I, Foucault (1988/1999) nos fala da instauração de uma normatização do sexo:

\section{POLÊM!CA | Revista Eletronica da Ueij}




\begin{abstract}
A sexualidade é então cuidadosamente encerrada. Muda-se para dentro de casa. A família conjugal a confisca. E absorve-a inteiramente, na seriedade da função de produzir. Em torno do sexo, se cala. O casal, legítimo e procriador, dita a lei. Impõese como modelo, faz reinar a norma, detém a verdade, guarda o direito de falar, reservando-se o princípio do segredo. No espaço social como no coração de cada moradia, um único lugar de sexualidade reconhecida, mas utilitário e fecundo: o quarto dos pais. Ao que sobra só resta encobrir-se; o decoro das atitudes esconde os corpos, a decência das palavras limpa os discursos. E se o estéril insiste, e se mostra demasiadamente, vira anormal: receberá este status e deverá pagar as sanções. (FOUCAULT, 1988/1999, pp. 9-10).
\end{abstract}

Portanto, Foucault (1988/1999) considera que há uma série de dispositivos de poder sobre a sexualidade, isto é, discursos de regulamentação que a controlam. Desta forma, os discursos sobre a sexualidade aparecem em precisos contextos sócio-históricos como tentativa de normatizar as práticas sexuais aos padrões estabelecidos, já que o controle do corpo e da sexualidade permite o controle da vida social e política.

Estas ditas verdades sobre a sexualidade, além de serem dispositivos de controle que buscam normatizar as ações e relações, agem sobre os sujeitos de forma a criar a ilusória crença da naturalização do pensamento que, por sua vez, marca a episteme de uma época. Pode-se dizer que a sexualidade é uma construção inseparável do discurso e do jogo do poder em que é constituída, sendo um aspecto para o modo de subjetivação do indivíduo (SALLES \& CECCARELLI, 2010).

Se até o final do século XVIII a pastoral cristã, o direito canônico e a lei civil controlavam o que era lícito e ilícito em relação à sexualidade, ao longo do século XIX é a medicina que passa paulatinamente a ocupar o lugar da verdade e saber sobre o sexo, acarretando uma transferência da competência dos saberes dos experts religiosos para os da medicina. Todavia, a ciência acaba sendo também subordinada pelos imperativos de uma moral, cujas classificações reiteraram sobre a forma de normas médicas (FOUCAULT, 1988/1999).

Estabelece-se a sexualidade "perigosa" e a "sadia", bem como a biologização da diferença dos sexos como base fundadora de toda sexualidade legítima. Assim, os grandes psiquiatras e sexólogos do século XIX esforçaram-se para traçar um "herbário dos prazeres", que classificava toda e qualquer forma de sexualidade além dos fins reprodutivos. Como refere Salles e Ceccarelli (2010, p. 21):

Um minucioso inventário das práticas sexuais que escapam os ditames morais foi repertoriado e etiquetado, fazendo surgir novas formas de perversões. Dentro de uma

\title{
POLÊM!CA | Revista Eetrônica da veri
}


perspectiva higienista e repressiva, discutiam-se os efeitos nocivos da sexualidade: práticas contra a natureza, o perigo da masturbação, do coito interrompido, vida conjugal insatisfatória [...] (SALLES \& CECCARELLI, 2010, p. 21).

A família se transformou em um espaço fundamental para o processo social de medicalização e construção do biopoder: as crianças precisam ser acompanhadas desde o nascimento até a maturidade para evitar desvios orgânicos e funcionais na sua formação, transformando-se alvo crucial da biopolítica (BIRMAN, 1999).

É que segundo Foucault (1926c/2008), a partir do século XVIII, as sociedades ocidentais modernas retomam o fato biológico fundamental de que o ser humano constitui a espécie humana. $\mathrm{O}$ conjunto de mecanismos pelos quais a espécie humana constitui suas características biológicas fundamentais, a partir daquele século, entra na política, ou melhor, em uma estratégia política geral de poder denominada de biopoder, ou seja, uma política de gestão dos corpos e da vida que se constituiu na nova tecnologia de poder da Modernidade.

O controle da reprodução passa a ser um tema privilegiado. Como afirma Birman (p.63): "a reprodução da espécie e a constituição específica de uma medicina feminina centrada no parto impuseram-se como dimensões fundamentais do biopoder". Desta forma, o corpo da mulher foi devidamente medicalizado, junto com o da criança e a totalidade da existência familiar foi catalisada pelo discurso da medicina social, da higiene e da saúde pública.

A função da sexualidade passa a ser a reprodução e o que pudesse interferir ou competir com a finalidade reprodutora seria uma ameaça para a sociedade, concebida pelas exigências da biopolítica. $O$ discurso passa a promover uma perfeita adequação entre as mulheres e o conjunto de atributos, funções, predicados e restrições que definia sua natureza e que era denominado de feminilidade, isto é, o recato, docilidade, afetividade mais desenvolvida, a receptividade passiva em relação aos desejos e necessidade dos homens e a geração dos filhos. Eis a associação entre a mulher e a maternidade (ALMEIDA, 2012).

De maneira paradoxal, acreditava-se que a natureza feminina precisaria ser domada pela sociedade e educação para não desviar as mulheres do destino de sua suposta essência, que deveria corresponder a ser esposa e mãe. Maternidade passa a ser considerado um instinto e um imperativo do ser mulher, enquanto o desejo e prazer feminino passam a ser vistos como maléficos e pecaminosos (BIRMAN, 1999).

\section{POLÊM!CA | Revista Eletronica da Ueij}


Com o erotismo esvaziado de virtudes e estigmatizado como pura negatividade, a mulher desejante passou a figurar uma possibilidade real para o mal e para o desvio social, considerada perigosa, precisando ser corrigida medicamente em nome da higiene social, com fim de impedir a degeneração da espécie (BIRMAN, 1999).

É dessa forma que a medicina passa a atuar perante as mulheres a partir de um modelo binário de dois opostos: a mulher boa (aquela que é mãe) e a mulher má (a sensual), considerada um risco social. Esta atuação produz efeitos até os dias atuais e teve repercussões tanto no início da epidemia da aids, como nas atuais formas de atuação em relação a sexualidade feminina.

\section{A feminização da epidemia: sequelas atuais da moral médica}

Apesar do reconhecimento de que a aids também se estende às mulheres, verifica-se que a moralização da medicina incide na feminização da epidemia e nas práticas que envolvem a sexualidade feminina. Um exemplo disso é o desconhecimento do fenômeno da "feminização da aids", pouco difundido nos meios de comunicação e nas Unidades Básicas de Saúde.

A expressão "feminização" foi postulada teoricamente pela vigilância epidemiológica a partir de 1990, entretanto, diferentemente de outros termos que nasceram no campo científico, não se tornou um termo popular por meio da circulação de informações midiáticas, permanecendo obscuro e desconhecido ao público em geral (MOREIRA \& LIMA, 2008).

Ao permanecer circunscrito ao campo científico político-institucional das organizações governamentais e não governamentais, a feminização da epidemia da aids se tornou um problema pouco difundido fora dos meios acadêmicos e científicos, desconhecido entre as próprias mulheres, o que implica na desinformação da população feminina e contribui negativamente para disseminação de práticas preventivas e debates de empoderamento da mulher. Como afirmam as autoras:

a veiculação da ideia da feminização da aids poderia torná-la uma conquista da cultura, se, a serviço da qualidade de vida das populações, fosse acessível ao público em geral, ao mesmo tempo que indicasse novas possibilidades de compreensão do problema. Ao alcançar mídia e massas, teriam grande serviço a prestar ao debate público, problematizando vulnerabilidade das mulheres e a infecção do HIV (MOREIRA \& LIMA, 2008, p. 115).

\section{POLÊM!CA | Revista Eletronica da ver}


Com a falta de informação e discussão sobre feminização da epidemia, a aids não se torna uma preocupação entre as mulheres, que continuam se expondo a práticas de risco pela falta de informação. Para além, as mulheres continuam imersas ao imaginário popular pautado em uma moral heteronormativa, que pressupõe a garantia de proteção no casamento entre um homem e uma mulher, ao passo que aqueles que vivenciam sua sexualidade fora de uma matriz normativa poderão ser considerados como vulneráveis a contaminação. Em outras palavras, as prostitutas e os gays ainda são os estigmatizados como os disseminadores de uma doença mortal.

Outro fator importante é em relação ao preservativo feminino, com pouca distribuição, divulgação e esclarecimento, sua utilização é ínfima, sendo irrisória entre as mulheres que desconhecem seu benefício, seu manejo, quiçá sua existência. A divulgação única e exclusiva do preservativo masculino coloca a mulher em uma condição de desvantagem: a decisão de cuidar de seu corpo carece de um acordo com seu parceiro, visto que a autorização do uso no corpo masculino se torna imprescindível.

Além disso, Bastos (2001) ainda atenta para outro fator que envolve o uso de preservativos femininos no Brasil: a crescente taxa de esterilização, principalmente em mulheres mais pobres e mais jovens. Segundo esse autor, há uma disjunção entre práticas anticoncepcionais e de prevenção. Assim, a esterilização acaba subtraindo um elemento importante de motivação no uso da camisinha: a anticoncepção.

Em 2013, o Ministério da Saúde do Brasil realizou uma grande compra de preservativo feminino e retomou a sua disponibilização no Sistema Único de Saúde (SUS), contudo, este ainda ocorre de maneira desproporcional em relação ao preservativo masculino e sem estratégias de divulgação, mantendo-o, então, na invisibilidade pelo pouco conhecido por mulheres em relação ao seu uso, seu acesso e seus benefícios (KALCKMANN, 2013).

\section{A divisão binária da mulher pela medicina}

Ao considerar os corpos femininos como objeto de controle rigoroso devido à função reprodutiva, a medicina realizou uma leitura binária da mulher, que direciona as ações médicas em relação à figura da mulher nos dias atuais, conforme mostra Barbosa (1995).

De acordo com autora supracitada, a mulher tem sido representada pelo sistema médico sob duas perspectivas: ora como prostituta, ora como procriadora. Em outras palavras, as moças sensuais, logo, más, são aquelas que estão sob risco eminente, enquanto as moças 
boas, "de família", são associadas à procriação, imunes a doenças "transgressoras". Assim, mulheres jovens com vida sexual ativa e que não trabalham com o sexo, acabam resumindo-se a exames preventivos, não tendo acesso ao exame de aids, tampouco a educação sexual de planejamento familiar. Muitas são orientadas a tomar anticoncepcionais para evitar a gravidez e apenas são relacionadas à possibilidade de aids durante o período da gestação, no tratamento pré-natal:

As mulheres em idade reprodutiva são as mais negligenciadas pelos programas, apesar de serem relativamente informadas sobre sexualidade e planejamento familiar, talvez até mais capazes de fazer escolhas maduras sobre seus comportamentos sexuais [...], não são identificadas como risco para aids, apenas quando grávidas são confrontadas com seus riscos potenciais de se infectar (BARBOSA, 1995, p.71).

Esta leitura dicotômica da mulher faz com que os programas médicos sejam relacionados essencialmente a saúde da mulher para a maternidade, paradigma que faz com que as campanhas preventivas não abordem a temática da aids como assunto de família, mas como um vírus perigoso que afeta aqueles transgressores. Logo, a maioria das campanhas se restringe às profissionais do sexo e aos homossexuais, especialmente em datas festivas, como o carnaval.

Este imaginário de que a mulher está protegida de uma possível doença transmissível ocorre justamente por uma questão cultural em que não se associa a mulher ao sexo. Nem mesmo quando "autorizada" a transar pela união estável, a mulher aparece como vulnerável ao risco, pois o casamento aparece com uma ilusória proteção, pautado no ideal de monogamia.

Por esperar que a mulher estabeleça família e ofereça filhos, não há orientação para o uso do preservativo nas relações matrimoniais, tampouco a realização de exames para a retirada do método, caso exista o desejo da gravidez. Sem orientações de planejamento familiar e sem realizar a testagem até encontrar-se grávida, a mulher se mantém exposta a possibilidades de contaminação.

Desta maneira, não se enxerga uma mulher solteira, que não seja prostituta, como uma candidata portadora a aids. E tão quanto alarmante: não se reconhece a mulher casada como vulnerável ao risco, como se o casamento e a união estável fossem garantias de segurança e proteção.

\section{POLÊM!CA | Revista Eletronica da veri}




\section{Nem santa, nem puta: mulher!}

É no contexto de controle dos corpos femininos e da divisão entre a mulher mãe e a mulher sexual que as profissionais do sexo aparecem como agentes de propagação de doenças sexualmente transmissíveis, verdadeiras ameaças à humanidade, vistas como representantes do reservatório do vírus HIV.

Todavia, tal concepção é uma distorção séria no entendimento de como a epidemia afeta as mulheres. De acordo com Berer e Ray (1997), de 1980 até 1997, no México, somente $0,8 \%$ de casos relatados de aids estavam entre as trabalhadoras do sexo, enquanto $9 \%$ era entre donas de casa. No Senegal, por exemplo, $50 \%$ das soropositivas no setor de um hospital para doenças infectocontagiosas não tinham outro fator exceto ser casada. Além disso, essas autoras trazem outros dados interessantes: o primeiro caso de aids registrado na Nigéria foi de uma menina de 13 anos e a primeira mulher diagnosticada com aids no México foi de uma dona de casa de 52 anos.

Considerar que aids é doença de mulher promíscua contribui para a discriminação da mulher como ser sexualmente ativo e é construído historicamente. Os primeiros cartazes sobre aids avisavam aos homens para terem cuidado com "aquelas mulheres", como também era feito em relação a outras doenças sexualmente transmissíveis durante a segunda guerra mundial (BERER \& RAY, 1997).

Culpar as trabalhadoras sexuais incentiva a culpa, o estigma e a discriminação contra todas as mulheres, além de permitir que os homens que contaminam as trabalhadoras do sexo e suas próprias esposas neguem que estão transmitindo o vírus a outros, bem como se elimina a possibilidade de esposas estarem transmitindo aids aos seus maridos, que podem levar as prostitutas.

Os estudos em trabalhadoras sexuais pouco se propõem a analisar a origem de sua contaminação, isto é, se a ocorrência advém de clientes, parceiros amorosos, drogas injetáveis ou transfusão sanguínea. O que já se sabe é que muitas prostitutas preservam-se nas relações com clientes, porém, não o fazem quando realizam ato sexual com seu companheiro amoroso (BERER \& RAY, 1997).

Estudo realizado pela antropóloga Denise Martin (1994) com mulheres com aids, revela que as justificativas para a contaminação do companheiro excluem qualquer possibilidade de questionamento de sua virilidade. Mesmo que a forma de transmissão do 
companheiro seja pela prática bissexual, o contágio pela prostituição é uma forma mais legítima de se contaminar, pois reforça a imagem viril do companheiro e o inocenta, porque ele poderia estar sendo contaminado sem saber, por uma mulher "errada".

A mulher aqui também aparece como algoz: é ela o ser nocivo que transmite o mal aos demais devido sua promiscuidade. Assim, socialmente, há um distanciamento entre a mulher promíscua - a puta má, mulher da vida e dos valores mundanos - e a mulher de família, considerada a moça boa a quem é atribuído o papel de cuidadora e de responsável pelo lar e pela transmissão de valores morais, o que pressupõe o ideal de fidelidade.

O fato é que mulheres jovens, adultas, idosas, casadas, solteiras e viúvas, monogâmicas, profissionais do sexo, com hábitos de vida ditos saudáveis ou drogaditas, isto é, independentemente de sua classe social ou de sua cor, apresentam um número crescente de contaminação. No Brasil, observa-se que a razão entre os sexos vem diminuindo ao longo da história, passando de 06 homens para cada 1 mulher no ano de 1989 para 1,7 casos em homem para 1 mulher, em 2011 (Ministério da Saúde, 2013).

\section{Considerações feministas: por visibilidades e prevenção}

Não é objetivo de este artigo negar os alcances científicos da medicina em relação a aids, afinal, reconhece-se os avanços em relação aos medicamentos que permitem maior qualidade de vida às pessoas que vivem com HIV, bem como do investimento em pesquisas para buscar a cura. Entretanto, não se pode ignorar que historicamente os saberes médicos, pautados em uma matriz heteronormativa, prejudicaram muitas mulheres e continuam prejudicando devido suas ineficazes medidas preventivas que, atravessadas em valores morais, excluem um grupo significativo de mulheres: as casadas, as que namoram, as solteiras e viúvas.

O ideal de fidelidade associado ao matrimônio, bem como a ilusória crença de proteção dos casais estáveis atravessam as práticas da medicina moderna, que, apesar dos avanços dos conhecimentos científicos (fisiológicos e biológicos), continuam a atuar atravessada pelo discurso moral.

Desta forma, temos uma política de saúde que exclui grande parte da população feminina que permanece aquém de informações sobre a crescente feminização da epidemia, da testagem de aids e de esclarecimentos sobre a importância do cuidado em relações estáveis, da falta de acesso ao preservativo feminino. 
Portanto, a tarefa política deste artigo é, além de divulgar o fenômeno da feminização da aids, aspecto importante para a prevenção de mulheres, demonstrar os efeitos que as concepções morais sobre o feminino, sexualidade e relação conjugal produzem em relação à epidemia da aids. É necessário sustentar as campanhas e prevenções ao risco de contaminação ao HIV a partir de outras bases, ou seja, bases que acolham a diversidade de formas de viver. Deste modo, faz-se necessário produzir políticas que levem em consideração as diversas formas de ser mulher e os também diversos usos que as mulheres fazem de sua sexualidade. $\mathrm{E}$ acima de tudo, apostar na potência, autonomia e na capacidade das mulheres em administrarem suas vidas, suas escolhas, suas relações.

\section{Referências}

BARBOSA, R. As mulheres, a AIDS e a questão metodológica: desafios. IN: CZERESNIA, D; SANTOS, E; BARBOSA, R.; MONTEIRO, S (Org). AIDS: pesquisa social e educação. Hucitec Abrasco: Rio de Janeiro, 1995.

BASTOS, F. A feminização da epidemia de AIDS no Brasil: determinantes estruturais e alternativas de enfrentamento. C. ABIA: Saúde Sexual e Reprodutiva, Rio de Janeiro, n. 03, 2000.

BASTOS, F.L; SZWARCWALD, C.L. Aids e pauperização: principais conceitos e evidências empíricas. Cad. Saúde Pública, 16 (01): 65-76. 2002.

BERER, M. \& RAY, S. Mulheres e HIV-AIDS: informação, ação e recursos relativos às mulheres e HIV, Aids, saúde reprodutiva e relações sexuais. São Paulo: Editora Brasiliense, 1997.

BIRMAN, J. Gramáticas do Erotismo: A feminilidade e as formas de subjetivação em psicanálise. Rio de Janeiro: Civilização Brasileira, 2001.

BRASIL. Ministério da Saúde. Brasília, DF, Brasil. Disponível em: <http://portalsaude.saude.gov.br/>. Acesso em: 01 set 2013.

FOUCAULT, M. A História da Loucura. São Paulo: Ed. Perspectiva, 2008a. (Originalmente publicado em 1926a). $\overline{1926 b) .}$

O Nascimento da Clínica. Rio de Janeiro: Forense Universitária, 2008b. (Originalmente publicado em $\overline{1926 c) .}$

O Nascimento da Biopolítica. São Paulo: Ed. Martins Fontes, 2008c. (Originalmente publicado em

A História da Sexualidade I: a vontade de saber. Rio de Janeiro: Edições Graal, 1999. (Originalmente publicado em 1988).

JAMES, B. \& WERJ, P. O preservativo feminino. In: BERER, M. \& RAY, S. Mulheres e HIV-AIDS: informação, ação e recursos relativos às mulheres e HIV, Aids, saúde reprodutiva e relações sexuais. São Paulo: Editora Brasiliense, 1997.

\section{POLÊM!CA | Revista Eletronica da ver}


KALCKMANN, S. Preservativo feminino e dupla proteção: desafios para os serviços especializados de atenção às DSTs e Aids. Temas psicol., Ribeirão Preto, v. 21, n. 3, dez. 2013.

LABAKI, M. E. P. Morte. São Paulo: Casa do Psicólogo, 2001.

LIMA, M.L.C \& MOREIRA, A.C. AIDS e feminização: os contornos da sexualidade. Rev. Mal-Estar Subj. [online], vol.8, n.1, pp. 103-118. 2008.

RANCIÈRE, J. O Desentendimento. São Paulo: Editora 34, 1996.

Recebido em: 15/04/2015.

Aceito em: 11/05/2015. 